Copyright (C1996, American Institute of Aeronautics and Astronautics, Inc.

AIAA Meeting Papers on Disc, July 1996

A9637142, AIAA Paper 96-2969

\title{
The D-100 performance and plume characterization on krypton
}

\author{
Colleen Marrese \\ Michigan Univ., Ann Arbor
}

James M. Haas

Michigan Univ., Ann Arbor

\section{Matthew T. Domonkos}

Michigan Univ., Ann Arbor

\author{
Alec D. Gallimore \\ Michigan Univ., Ann Arbor
}

Sergei Tverdokhlebov

Central Scientific Research Inst. for Machine Building, Kaliningrad, Russia

Charles E. Garner

JPL, Pasadena, CA

\section{AIAA, ASME, SAE, and ASEE, Joint Propulsion Conference and Exhibit, 32nd, Lake Buena Vista, FL, July 1-3, 1996}

\begin{abstract}
The performance of a D-100 thruster with anode layer, designed to operate on xenon at a nominal operating power of $4.5 \mathrm{~kW}$, was investigated during operation on krypton. This evaluation was preliminary to a more thorough investigation of D-100 operation on alternative propellants, such as mixtures of krypton and xenon. Several operating regimes were evaluated ranging in power from 0.9 to $4.5 \mathrm{~kW}$. Two of these regimes were explored extensively using Faraday, RPA and emissive probes, with the second regime being of particular importance for orbit raising missions. Direct thrust measurements were taken with an inverted ballistic pendulum thrust stand. Thrust was also calculated using average velocity and ion density measurements, and this method yielded results in agreement with the thrust stand data. Thruster performance was compared to operation on Xe and showed a 20 percent efficiency loss at the same specific impulse during operation on krypton. (Author)
\end{abstract}




\title{
TheD-100 Performance and Plume Characterization on Krypton
}

\author{
Colleen M. Marrese ${ }^{*}$, James M. Haas*, Matthew T. Domonkos ${ }^{\dagger}$, and Alec D. Gallimore ${ }^{\sharp}$ \\ The University of Michigan \\ Plasmadynamic and Electric Propulsion Laboratory (PEPL) \\ Ann Arbor, MI \\ Sergei Tverdokhlebov \\ TsNIIMASH-Export \\ Kaliningrad, Russia \\ Charles Garner ${ }^{\frac{*+}{4}}$ \\ Jet Propulsion Laboratory \\ Pasadena, Califomia
}

\begin{abstract}
The performance of a D-100 thruster with anode layer, designed to operate on xenon at a nominal operating power of $4.5 \mathrm{~kW}$, was investigated during operation on krypton. This evaluation was preliminary to a more thorough investigation of D-100 operation on alternative propellants, such as mixtures of krypton and xenon. Several operating regimes were evaluated ranging in power from 0.9 to $4.5 \mathrm{~kW}$. Two of these regimes were explored extensively using Faraday, RPA and emissive probes, with the second regime being of particular importance for orbit raising missions. Direct thrust measurements were taken with an inverted ballistic pendulum thrust stand. Thrust was also calculated using average velocity and ion density measurements, and this method yielded results in agreement with the thrust stand data. Thruster performance was compared to operation on Xe and showed a $20 \%$ efficiency loss at the same specific impulse during operation on krypton.
\end{abstract}

\footnotetext{
*Graduate Student. Aerospace Eng. Dept.

$\div$ Graduate Student. Aerospace Eng. Dept.. Member AIAA

${ }^{*}$ Assistant Professor. Aerospace Eng. Dept.. Member AIAA

+Executive Director

$\because$ Menber of the Technical Staff. Member AIAA
} 


\section{Nomenclature}

$d$ distance between RPA collector and grid, $\mathrm{m}$

$e$ electron charge. $\mathrm{C}$

$\langle E\rangle \quad$ average energy, $\mathrm{eV}$

$f(v)$ ion velocity distribution function

$I_{1}$ discharge current, A

$I_{t e} \quad$ secondary electron emission current, $A$

$I_{y^{\prime \prime}} \quad$ specific impulse, sec

$J_{1} \quad$ ion current density, $\mathrm{A} / \mathrm{m}^{2}$

$J_{i_{r b}}$ ion current density measured by a Faraday

probe, $\mathrm{A} / \mathrm{m}^{2}$

$J_{f_{F}}$ ambient ion current density, $\mathrm{A} / \mathrm{m}^{2}$

$M, \quad$ ion mass. $\mathrm{kg}$

in mass flow rate. $\mathrm{mg} / \mathrm{s}$

$S_{m} \quad$ inside width of mesh orifice, $m$

$V_{d}$ discharge voltage, $\mathrm{V}$

$\gamma_{i} \quad$ secondary electron emission coefficient due to ion bombardment

$\eta$ propellant utilization fraction

$\phi_{r} \quad$ ion retarding grid potential, $\mathrm{V}$

$i$ ion velocity, $\mathrm{m} / \mathrm{s}$

$\langle v\rangle, \quad$ average ion velocity, $\mathrm{m} / \mathrm{s}$

$\chi \quad$ open area fraction of RPA grid

$\lambda_{D} \quad$ Debyo length, $\mathrm{m}$

\section{Introduction}

The $\mathrm{D}-100$ is a $5 \mathrm{~kW}$ class hall thruster built by the Central Scientific Research Institute of Machine Building (TsNIIMASH) of Kaliningrad, Russia, and is currently being investigated in the U.S. as part of the Ballistic Missile Defense Organization's (BMDO) effort to develop Russian Hall effect thruster technology for western satellites. 1.2 This initiative seeks to facilitate the integration of Russian hall thrusters with U.S. spacecraft. The D-100 is a candidate thruster for planetary, stationkeeping, and orbit transfer applications. The advent of communications satellites with 11 to $15 \mathrm{~kW}$ of power has enabled the use of $5 \mathrm{~kW}$ class electric propulsion for stationkeeping and orbit transfer. Hughes currenlly plans to outfit their $10 \mathrm{~kW}$ class satellites with xenon ion ihrusters for stationkeeping, a decision which promotes the acceptance of xenon thrusters on spacecraft. However, the most significant benefits of electric propulsion yet realized will occur with the application of $5 \mathrm{~kW}$ class thrusters for orbit transfer. A solar electric orbit transfer vehicle (SEOTV) will reduce launch costs when compared to chemical OTV ${ }^{3}$.

The TAL was invented in the early-1960's as a highpower two stage electric thruster. ${ }^{+}$The single stage TAL was first developed in the late 1970's when it was realized that near term satellites would have power generation capability on the order of one kilowatt. ${ }^{t}$ The difference in operation between the TAL and the SPT is due to the anode configuration and the magnetic field topography. In the single stage TAL, the anode extends to the physical exit plane of the thruster, and the strength of the radial magnetic field is maintained within a few millimeters of the exit plane. Consequently the ionization and acceleration regions are located primarily downstream of the thruster components. With the high energy ions generated effectively outside of the thruster, the sputter rate of thruster components is reduced compared to SPTs. While the edge in thruster life achieved by the reduced erosion rate is small, ' it may be sufficient to justify the use of TALs for very high total impulse $\left(10^{7} \mathrm{~N}-\mathrm{s}\right)$ missions. The relatively high thrust density and comparative insensitivity of thruster performance to input power level make the D-100 an attractive choice. The efficient power scaling of the D-100 enables the use of a single thruster for a variety of tasks, and eliminates costly evaluation of several thrusters to fulfill specific mission requirements. Consequently, in the competition for $3-5 \mathrm{~kW}$ class engines, the D-100 warrants the same level of investigation as SPTs and ion thrusters.

Like the SPT-100, the D-100 has been tested extensively in Russia and must now undergo performance, integration, and life testing in the U.S. before it can be accepted as flight hardware. This paper describes a preliminary performance evaluation of the D-100 on krypton. Krypton was chosen both as part of an investigation into alternative propellants for Hall thrusters and to provide a cost effective means to evaluate general thruster performance characteristics and plume properties. Initial testing at the University of Michigan (UM) investigated the physical feasibility of using krypton as an alternative propellant, and similar performance tests conducted at the Jet Propulsion Laboratory (JPL) using xenon are reported for comparison.5 The emphases of the tests at the UM were direct thrust measurement and plume characterization. Thrust measurements were taken to evaluate thruster performance, and the plume was investigated both to obtain data for analyzing integration issues and to provide an indirect estimate of the thrust.

\section{Experimental Apparatus}

The D- 100 shown schematically in Figure 1 was constructed by TSNIIMASH in Kaliningrad. Russia. The anode was made of graphite which allowed high temperature operation and a low sputter yield. The guard rings were also constructed from graphite. A barium oxide impregnated tungsten hollow cathode 
was provided by JPL. The orientation was chosen to provide uniform neutralization of the ion beam, and the keeper was operated continuously to facilitate quick restarts of the thruster. Micrometer valves inside the vacuum chamber were used to control the flow of 99.999 percent pure $\mathrm{Kr}$ to the cathode and anode independently. MKS flow controllers were used to monitor the flowrate, and the system was calibrated to an accuracy of $+1-0.2 \mathrm{mg} / \mathrm{s}$ of krypton for the total flow to the thruster. A schematic of the electrical circuit for the D-100 is shown in Figure 2. A $105 \mu \mathrm{F}$ capacitor and a $3.5 \Omega$ resistor were used to filter the discharge. Tektronix 1000:1 voltage probes were used with a digital oscilloscope to measure the average voltage over $10 \mathrm{~ms}$ to an accuracy of $+/$ $0.9 \mathrm{~V}$. The average discharge current was measured to an accuracy of $+1-0.07 \mathrm{~A}$ using a Tektronix A6303 current probe and a digital oscilloscope.

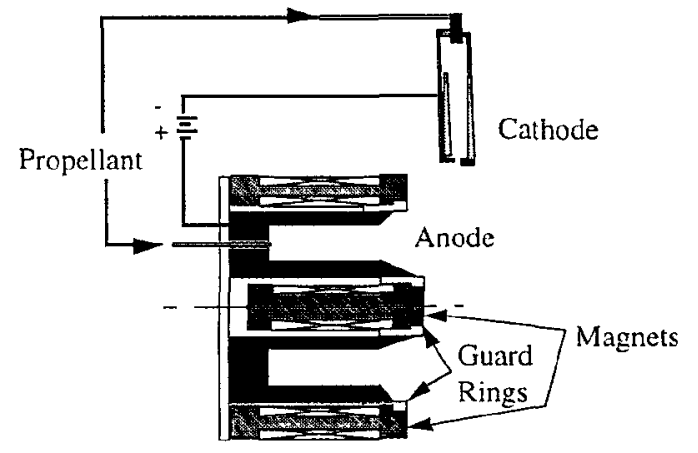

Fig. 1 - D-100 Schematic

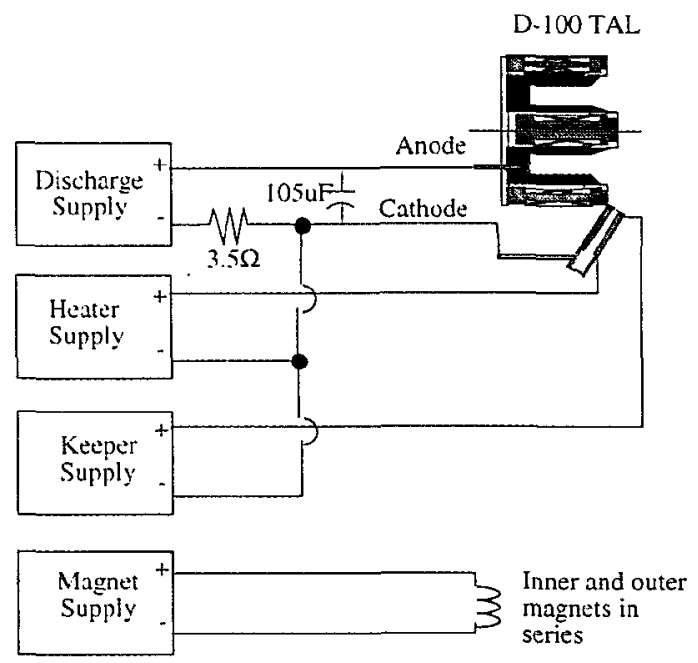

Fig. 2 - Electrical Schematic for the D-100
Testing of the thruster on krypton was conducted at the UM Plasmadynamics and Electric Propulsion Laboratory (PEPL) in the $6 \mathrm{~m}$ by $9 \mathrm{~m}$ vacuum tank shown schematically in Figure 3 . The chamber was pumped by six $0.8 \mathrm{~lm}$ diameter oil diffusion pumps which were backed by two mechanical blowers and four mechanical pumps. A Polycold system over two of the diffusion pumps removed water vapor from the tank atmosphere. The diffusion pumps provided a pumping speed of approximately $48000 \mathrm{~L} / \mathrm{s}$ of krypton. Two ion gages measured the tank pressure during testing. The pressure was approximately $3.8 \times 10^{-5}$ Torr during testing. The thrust stand was located on the thruster station shown in Figure 3, which placed the thruster axis approximately coincident with the chamber axis, minimizing the effects of facility interference.

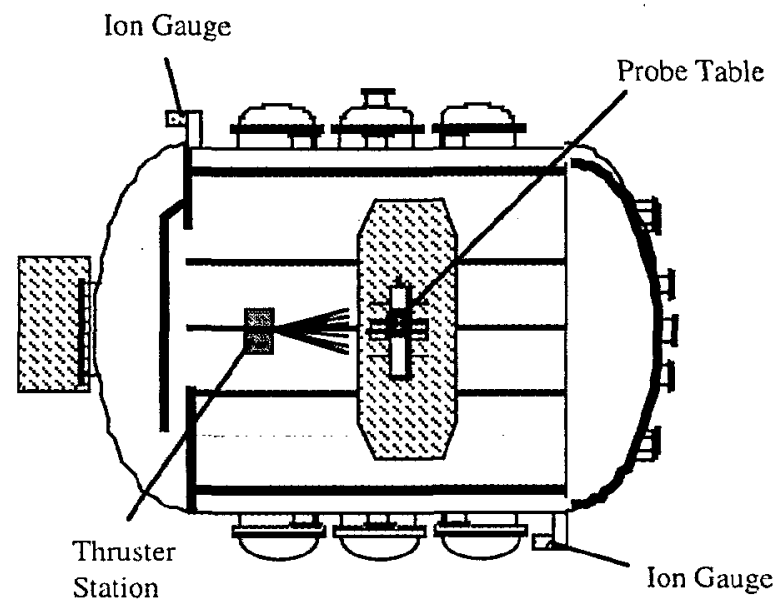

Fig. 3 - The University of Michigan Vacuum Chamber

Thrust Stand

Figure 4 depicts the thrust stand used to test the D100. The thrust stand is an inverted ballistic pendulum based on the NASA Lewis Research Center design. Power was supplied to the thruster through a flexible kapton coated ribbon cable. Four $3.2 \mathrm{~mm}$ diameter stainless steel tubes, arranged in a "slinky" fashion, provided propellant to the thruster and water cooling for the thruster mount. A water cooled shroud was used to minimize the error in thrust measurements associated with thermal drift of the thrust stand components. A Schaevitz 100HR Linear Voltage Differential Transformer (LVDT) was used to measure displacement with a resolution of $2.5 \times 10^{-3}$ $\mathrm{mm}$. Thrust stand inclination was monitored using a Spectron Systems Technology MUPI-2 inclinometer with resolution better than 1 arc second. A motor was used to control the thrust stand inclination during 
thrust measurements. Another motor was used to deploy weights during calibrations of the thrust stand. Calibrations were performed prior to and following the thrust measurements to maximize accuracy, and thrust measurements were based on an average of the two calibrations. The resultant thrust measurements were accurate to within $3.2 \mathrm{mN}$.

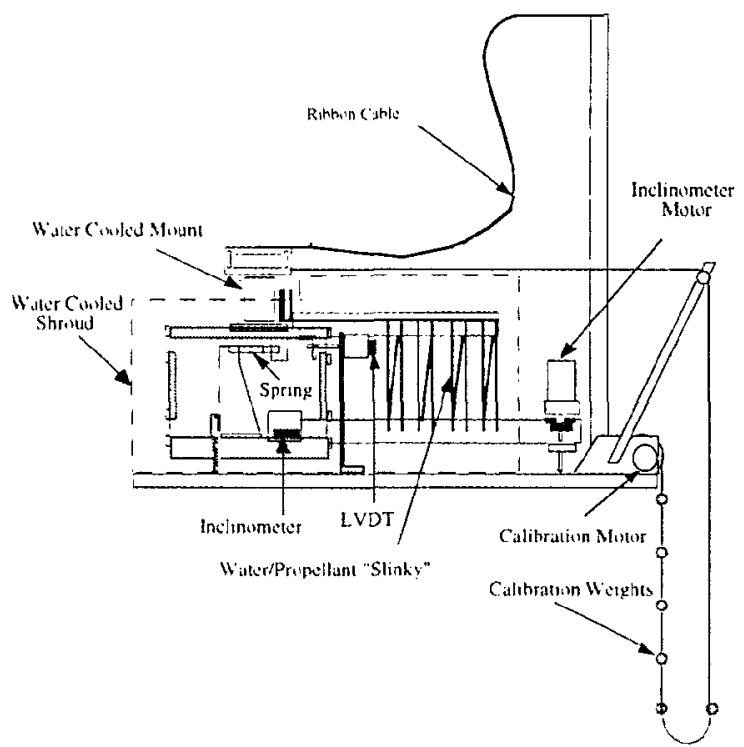

Fig. 4 - Schematic of the Thrust Stand

\section{Probe Diagnostics}

The plume of the thruster was investigated using the Faraday probe, emissive probe and retarding potential analyzer (RPA) shown in Figure 5. The probes were mounted to a boom on a probe positioning table that could move axially, radially and rotate through $180^{\circ}$.

Faraday probes. like the one shown in Figure 5, were supplied by JPL. They were used to measure ion current density at 5 degree increments, $+1-90$ degrees off axis. at at distance of $.5 \mathrm{~m}$ and $1 \mathrm{~m}$ from the thruster exit. The Faraday probe consisted of a stainless stee] collector isolated from and mounted flush with the edge of a stainless steel shield. The shield was biased $-30 \mathrm{~V}$ with respect to ground. The collector was biased $-30 \mathrm{~V}$ with respect to ground to retard any incoming electrons. The surface of the collector was spray coated with tungsten to reduce secondary electron emission.

Emissive probes. shown in Figure 5b. were used to measure the local plasma potential. The emitter was a $5.1 \times 10^{-2} \mathrm{~mm}$. diameter tungsten wire in a hairpin loop configuration. Because the first grid of the RPA floats. this measurement was necessary to determine the true retarding putential of the retarding potential analyzer probe. Emissive probes were employed in a configuration such that the probes floated as they were heated to increasing levels of emission. As probe emission increased, probe potential increased until it reached plasma potential. Above plasma potential, only electrons with sufficient thermal energy were able to escape from the probe into the plasma. Since the majority of the electrons did not have enough energy to escape, the probe potential only slightly increased with increasing temperature. The position of the knee that separated the two different emission regions defined the plasma potential. Figure 6 shows a typical V-I characteristic that was used to determine the plasma potential. Plasma potential measurements were then used to determine the effective ion decelerating potential of the probe due to the initial acceleration of ions between the plasma and floating grid. This difference is then subtracted from the measured ion decelerating potential.

The RPA consisted of three stainless steel grids and a collector isolated from each other by ceramic and Teflon insulators. This assembly, with the exception of the floating grid, was isolated from the stainless steel probe body. The entrance orifice had a diameter of $7 \mathrm{~mm}$, however, the effective collection area was reduced to $5.89 \mathrm{~mm}^{2}$ due to the presence of the grids. Table 1 summarizes the open area fraction, $\chi$, of each grid, wire diameter, $\phi_{s}$, and distance, $d$, from the collector. To ensure that the plasma did not invade the analyzer, this RPA was limited to operation in environments where the Debye length, $\lambda_{D}$, satisfied the criterion that $S_{m} / 2>S_{m} / 2$, where $S_{m}$ was the inside width of a mesh orifice. The first grid and shield were allowed to float in order to minimize the probe's disturbance of the surrounding plasma. The electron retarding grid (ERG) was biased $-30 \mathrm{~V}$ with respect to ground in order to retard all incoming electrons. Since the cathode potential was never more than $15 \mathrm{~V}$ below probe floating potential, $30 \mathrm{~V}$ was sufficient to retard more than $99.999 \%$ of the incoming electrons when the electron temperature was on the order of $3 \mathrm{eV}$. Spectroscopic measurements showed that the average electron temperature was $3 \mathrm{eV}$, although the temperatures ranged from $1 \mathrm{eV}$ to $5 \mathrm{eV}$. The collector was maintained near ground potential. The bias of the ion retarding grid (IRG) was varied between 0 and $500 \mathrm{~V}$ with respect to ground in order to determine ion energy distributions. 


\begin{tabular}{lccc} 
Grid & Floating & $E R G$ & $I R G$ \\
\hline$\chi$ & .50 & .44 & .71 \\
$\phi_{s}(\mathrm{~mm})$ & .112 & .028 & .042 \\
$S_{m}(\mathrm{~mm})$ & .266 & .056 & .225 \\
$\mathrm{~d}(\mathrm{~mm})$ & 15.0 & 11.5 & 6.0
\end{tabular}

Table 1 - RPA Dimension

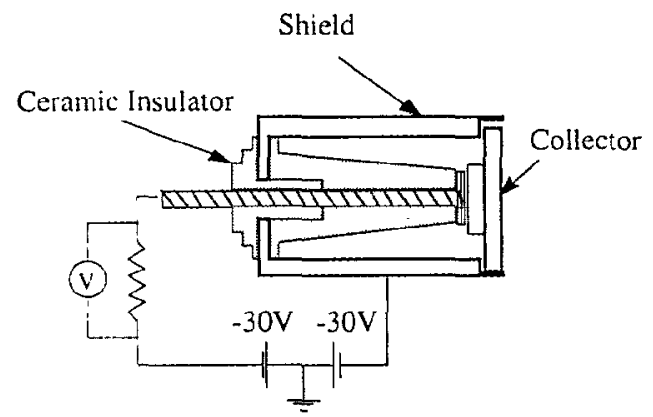

5a) Faraday Probe Built by the PEPL and JPL

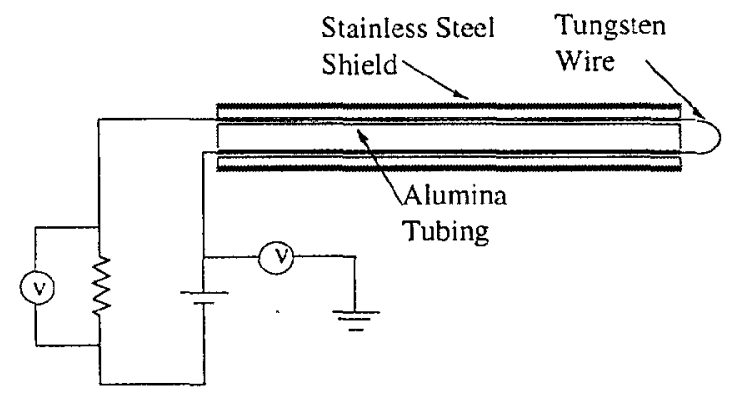

5b) Emissive Probe

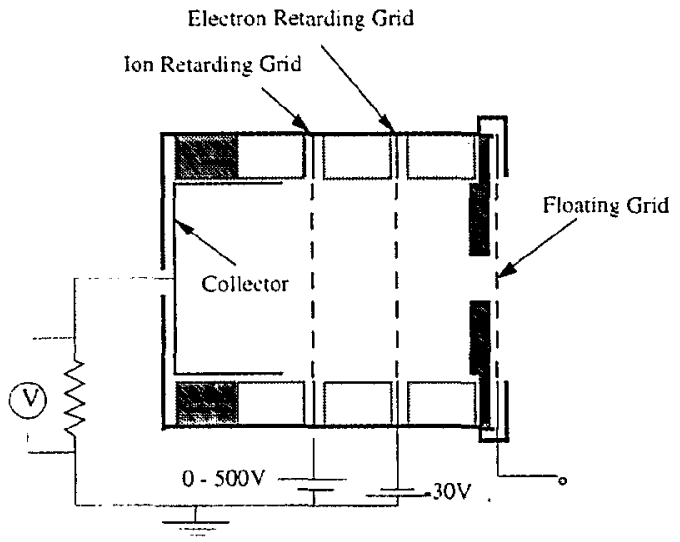

5c) RPA Built by the Moscow Aviation Institute

Fig. 5 - Diagnostic Probes

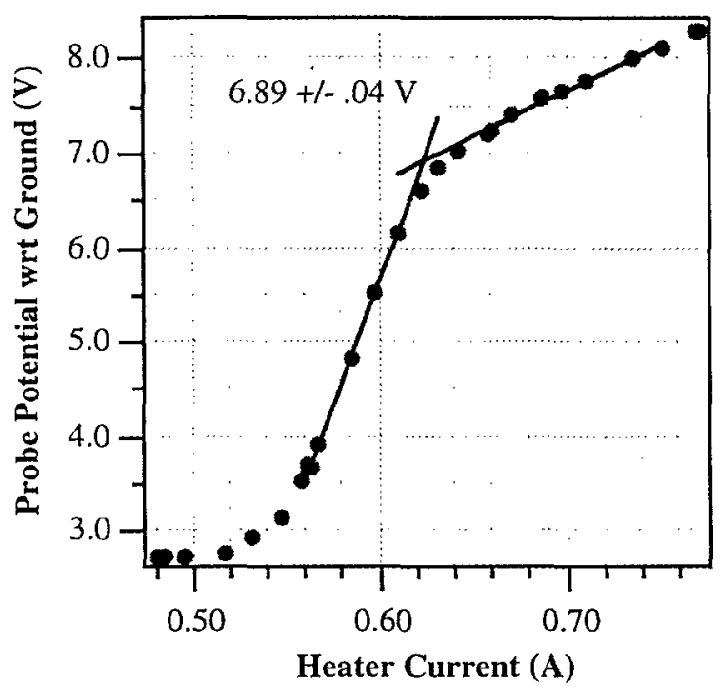

Fig. 6 - Emissive Probe V.I Characteristic Sample

Results and Discussion

The D-100 was operated at flow rates ranging from $6.7 \mathrm{mg} / \mathrm{s}$ to $9.3 \mathrm{mg} / \mathrm{s}$ and discharge voltages from 40 to 515 volts, the upper limit being set by the power supply. The discharge power varied from 0.9 to $4.5 \mathrm{~kW}$. The objective was to investigate the dependance of the thruster performance and plume characteristics on discharge voltage and mass flowrate. The electromagnet current was adjusted to minimize the discharge current and the amplitude of the current oscillations. The magnet current is presented in Table 2 for the $8.3 \mathrm{mg} / \mathrm{s}$ and $9.3 \mathrm{mg} / \mathrm{s}$ operating conditions. The instantaneous current and voltage are shown in Figure 7 for a stable discharge.

\begin{tabular}{ccc}
$\begin{array}{c}\text { Total Flowrate } \\
(\mathrm{mg} / \mathrm{s})\end{array}$ & $\begin{array}{c}\text { Cathode Flow } \\
(\mathrm{mg} / \mathrm{s})\end{array}$ & $\begin{array}{c}\text { Magnet Current } \\
(\mathrm{A})\end{array}$ \\
\hline 8.3 & 0.35 & 0.49 to 0.54 \\
9.3 & 0.40 & 0.43 to 0.59
\end{tabular}

Table 2 - Electromagnet Current Variations 


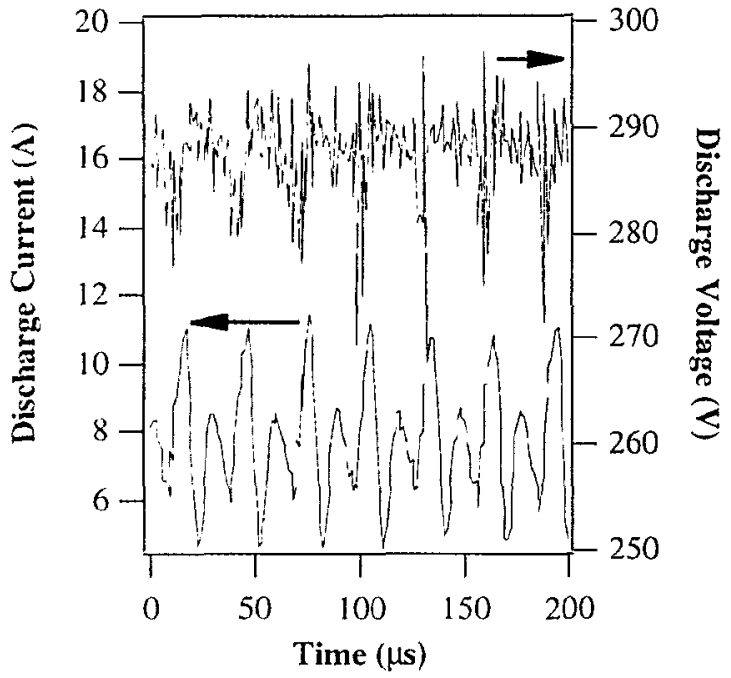

Fig. 7 - Typical Discharge Current and Voltage Fluctuations at $6.7 \mathrm{mg} / \mathrm{s}$ of $\mathrm{Kr}$

\section{Performance}

Specific impulse is plotted versus discharge voltage in Figure 8. Xenon data by Garner ${ }^{5}$ are included for comparison. This plot shows that the specific impulses obtained with krypton nearly matched those with xenon at much lower flowrates. These results were consistent with previous studies ${ }^{6}$ linking atomic mass ratios with performance ratios. At $300 \mathrm{~V}$, a . xenon flow of $5.5 \mathrm{mg} / \mathrm{s}$ provided a specific impulse of $1444 \mathrm{~s}$, while $8.3 \mathrm{mg} / \mathrm{s}$ of krypton, 1.5 times the mass flow of xenon, yielded $1456 \mathrm{~s}$. The additional flow was necessary to induce a higher ionization fraction. as discussed below.

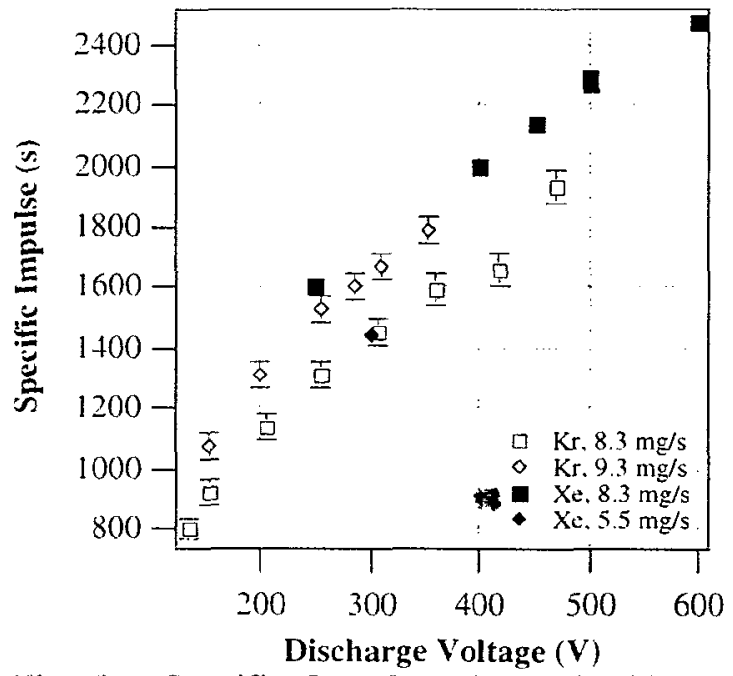

Fig. 8 - Specific Impulse of the D-100 on Krypton

(Xe Data from Garner ${ }^{5}$ )
Figure 9 illustrates the dependence of efficiency on discharge voltage and mass flowrate. Again, xenon data are taken from Garner. ${ }^{5}$ Efficiency was calculated based on the entire mass flow and the discharge power. The total and cathode flowrates are given in Table 2. Thruster power fractions are presented in Table 3. These data show a twenty percent decrease in efficiency compared to xenon. At $9.3 \mathrm{mg} / \mathrm{s}$, the efficiency decreases slightly with increasing discharge voltage after an initial rise. This feature was attributed to ohmic heating of the power strip prior to failure. The overall reduction in efficiency has been attributed in part to a larger anode fall voltage with krypton, a $1.87 \mathrm{~V}$ difference in ionization potentials, and the related reduction in ionization fraction. ${ }^{6}$ Spectroscopic analysis with a $0.5 \mathrm{~m}$ spectrometer showed a relative increase in the number of excited neutrals in the discharge when compared to xenon in the SPT-100. suggesting a reduction in the ionization fraction. At higher flowrates, and consequently increased discharge currents, the current density produces a larger ionization fraction and improved efficiency. ${ }^{6}$ Since mixtures of xenon with lower atomic mass propellants increase the ionization fraction, it is expected that $\mathrm{Xe}-\mathrm{Kr}$ mixtures will improve efficiency compared to krypton.

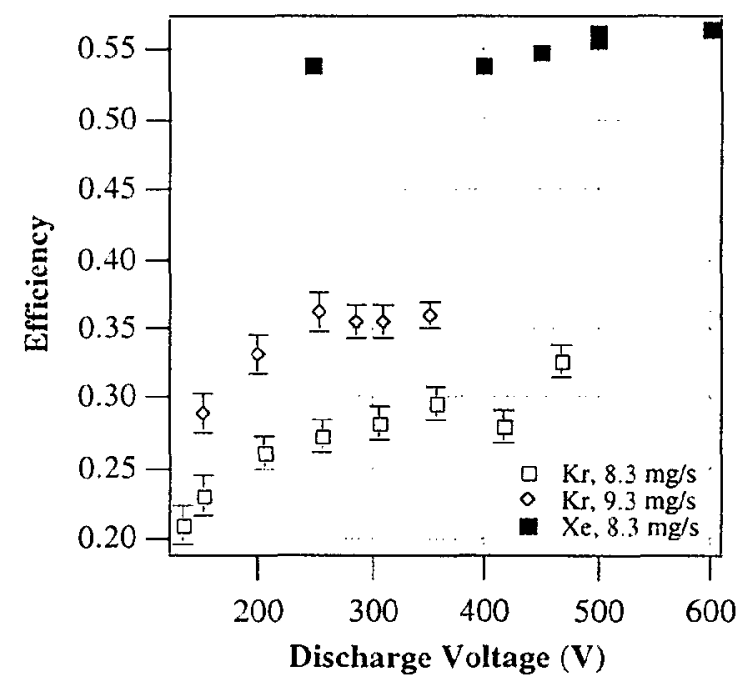

Fig. 9 - Efficiency of the D-100 on Krypton

(Xe Data from Garner ${ }^{5}$ )

\begin{tabular}{cccc}
$\begin{array}{c}\text { Mass Flow } \\
(\mathrm{mg} / \mathrm{s})\end{array}$ & Discharge & Keeper & Magnets \\
\hline 6.7 & 93.9 to 98.4 & 1.5 to 6 & 0.1 \\
8.3 & 96.4 to 99 & 0.8 to 3.4 & 0.2 \\
9.3 & 97.5 to 98.9 & 1.0 to 2.4 & 0.1
\end{tabular}

Table 3 - Power Fractions for the D-100 
Thrust Density Distributions

A second, indirect method was used to estimate thrust. This method employed a Faraday probe, emissive probe, and RPA to determine the ion current density, plasma potential, and average ion energy. The two thruster operating regimes explored are described in Table 4.

\begin{tabular}{cccccc} 
Regime & $\begin{array}{c}V d \\
(V)\end{array}$ & $\begin{array}{c}I d \\
(A)\end{array}$ & $\begin{array}{c}\dot{m} \\
(\mathrm{mg} / \mathrm{s})\end{array}$ & $\begin{array}{c}T \\
(\mathrm{mN})\end{array}$ & $\begin{array}{c}I s p \\
(s)\end{array}$ \\
\hline I & 278 & 7.71 & 6.57 & 95 & 1472 \\
II & 417 & 9.48 & 8.3 & 135 & 1661
\end{tabular}

Table. 4 - Operating Parameters for Regimes I and II

The ram ion curtent density measurements are presented in Figure 10 . In all of the probe measurements, the cathode was located on the negative angle side. A measurement of the ambient ion current density, obtained with the faraday probe oriented directly away from the thruster, is presented in Figure 11. The ambient ions contributed about $1.5 \%$ of the ram ion current density measured. The average ion kinetic energies were used to determine secondary electron emission coefficients for calculations of the secondary electron emission current, lee. The true ion current density is determined using Equation 1.

$$
J_{t}=J_{i_{F P}}-\gamma_{i}(\langle E\rangle) J_{i_{F P}}-J_{i_{F P, t}}
$$

where

This equation for $\gamma_{i}$ was generated from data published by Brown, S. C. ${ }^{7}$ Average ion energy was determined using emissive probe and RPA measurements. The measured plasma potential distributions are presented in Figure 12. Ion energy distributions, generated with the RPA, were used to determine the average ion velocities using Equations 2 and 3 . The velocity distribution is written in terms of the ion retarding grid potential as

$$
f(\nu)_{i}=\frac{M_{i}}{e^{2}} \frac{-d I\left(\phi_{r}\right)}{d \phi_{r}}
$$

so that

$$
\langle\rangle_{i}=\frac{2 e}{M_{i}} \frac{\int \phi_{r}^{\frac{1}{2}} f\left(\phi_{r}\right) d \phi_{r}}{\int_{0}^{\infty} f\left(\phi_{r}\right) d \phi_{r}} \text { eq.3 }
$$

With these measurements, the thrust density was estimated every 5 degrees and total thrust, $T$, was calculated using Equation 4.

$$
T=\frac{m_{i}}{e} \iint J_{i}\langle v\rangle_{i} r^{2} \sin \Theta d \Theta d \Phi
$$

In regime $\mathrm{I}$, thrust was estimated from probe data taken at $.5 \mathrm{~m}$ because the RPA signals were much stronger there than at $1 \mathrm{~m}$. The performance of the thruster operating in a higher power regime that is suitable for orbit raising missions was explored for regime II. Thrust estimates were made from data taken at $1 \mathrm{~m}$ radius because of concern that the probe set-up was insufficiently robust to survive in the hostile environment. The propellant utilization fraction was the ratio of the integrated ion current density to the maximum ion current if all particles were singly ionized. Propellant utilization fractions were estimated from ion current densities measured with the Faraday probe and are presented in Table 5.

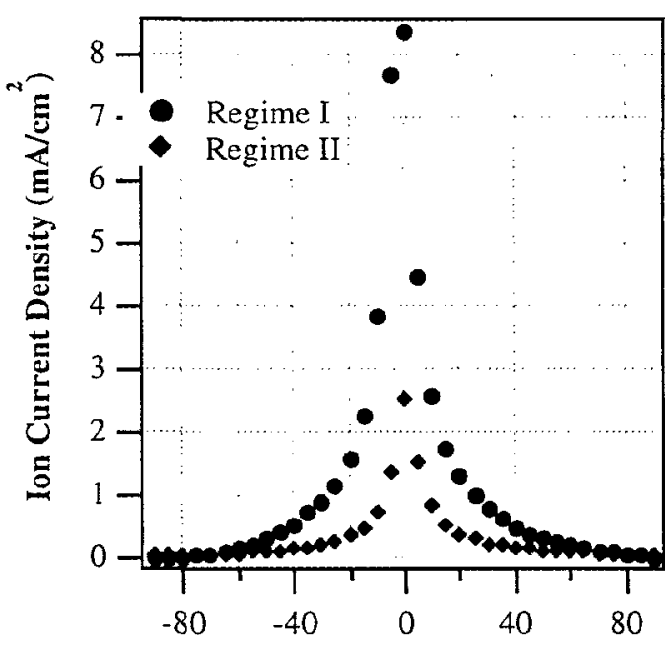

Angle with respect to Thruster Axis

Fig. 10 - Ion Current Density Taken at $0.5 \mathrm{~m}$ in Regime $\mathrm{I}$ and $1 \mathrm{~m}$ in Regime II. 


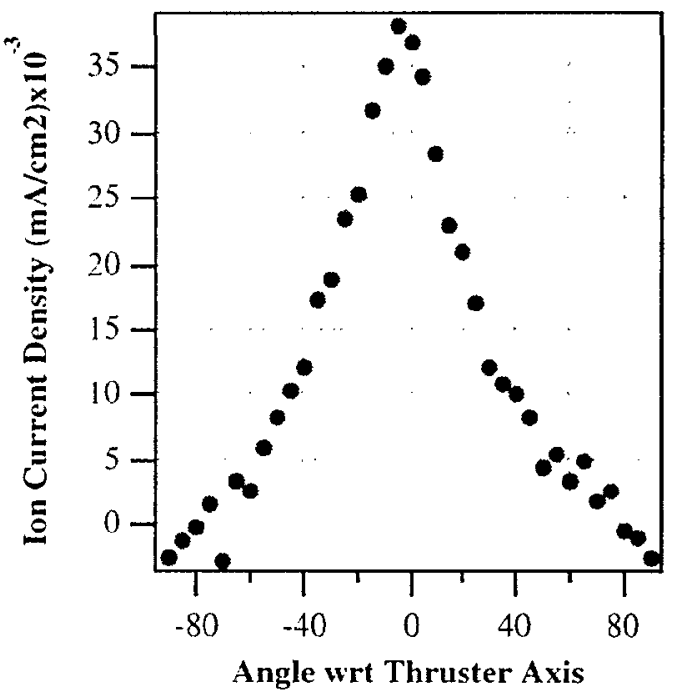

Fig. 11 - Ambient Ion Current Density in Regime I at $0.5 \mathrm{~m}$

Regime I Regime II

$\frac{\text { Regime }}{\eta_{i}}$ Regime II

Table 5 - Propellant Ionization Fraction

Note that the ionization efficiency for $.5 \mathrm{~m}$ exceeds $100 \%$. It was believed that this artificially high ionization fraction can be attributed to KrIII particles. The $.5 \mathrm{~m}$ spectrometer employed in this experiment detected the presence of KrIII. Velocity distribution functions determined by the RPA were characteristic of a plume with a significant amount of double ions. At $1 \mathrm{~m}$. the appearance of doube ions in the velocity distribution function functions decreased. Therefore, it was assumed that high ionization efficiencies can be attributed to double ions as well as errors inherent to the probe.

Plasma potential measurements show fluctuations around $2 \mathrm{~V}$ at $1 \mathrm{~m}$ and $.5 \mathrm{~m}$. While the resolution in the V-I curves suggested an error of less than one percent. the error inherent to the probe was as great as $30 \%$. This crror was a result of the voltage drop across the emitter which was as high as $1.5 \mathrm{~V}$ in this investigation.

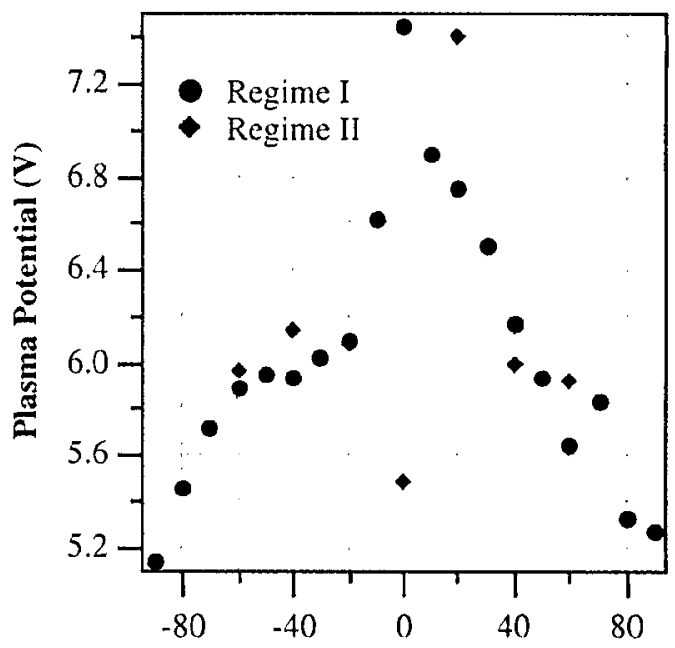

Angle with respect to Thruster Axis

Fig. 12 - Plasma Potential with respect to Ground

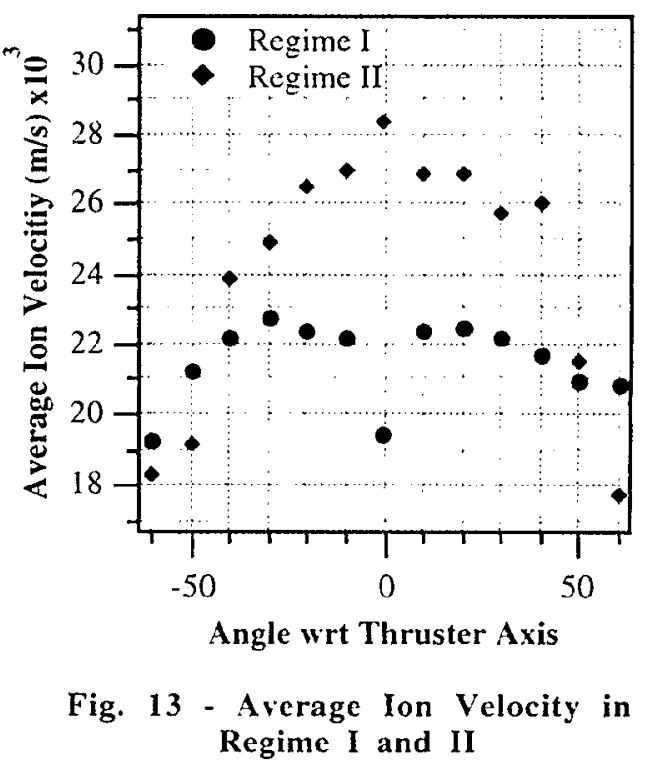

The trends observed in Figure 13 show a lower energy core at $.5 \mathrm{~m}$ in regime $\mathrm{I}$. This trend seemed to be characteristic of Hall thrusters because of the annular discharge chamber. The average ion velocity distribution taken in Regime II actually showed a higher energy core in the center. This distribution implied that an axial distance of $1 \mathrm{~m}$ was downstream of the focal point of the thruster. At different operating regimes it is unclear whether the structure of the velocity distribution curves will show similar 
structure evolution with distance downstream of the thruster.

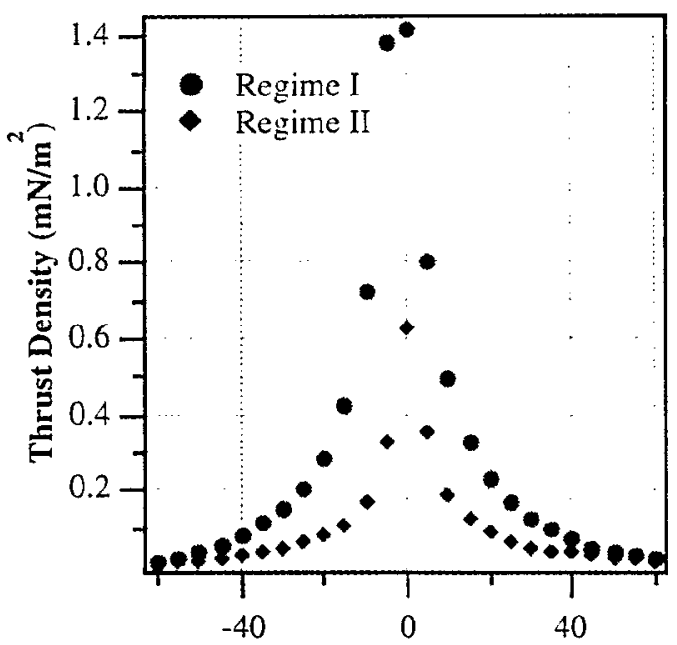

Angle with respect to Thruster Axis

Fig. 14 - Axial Thrust Density Distribution in Regime I and II

Table 6 presents the results of the thrust calculations from the probe measurements. The thrust density was integrated over a $60^{\circ}$ solid angle because RPA measurements were obtained only in that region. Thrust estimates made from measurements at $.5 \mathrm{~m}$ should be more accurate than $1 \mathrm{~m}$ because a larger percentage of the beam is contained within $60^{\circ}$ of the thruster axis. However at $60^{\circ}$, contributions of slightly less than a milliNewton were still being made at both $1 \mathrm{~m}$ and $.5 \mathrm{~m}$. Because thrust contributions were still significant at $60^{\circ}$, it was determined that $90^{\circ}$ sweeps are required to determine the total thrust generated. Since thrust measurements are already within $4 \%$ of the total, it is possible that this method will overpredict the total thrust generated. However, it has been proven that probes can be used to stimate thrust with respectable error. Further investigations are required to quantify this error.

\begin{tabular}{ccc} 
Thrust $(\mathrm{mN})$ & Regime $I$ & Regime $I I$ \\
\hline Measured & 95.5 & 135 \\
Calculated & 93.6 & 129
\end{tabular}

Table 6 - Comparison of Measured to Calculated Thrust

\section{Conclusions}

An investigation of the performance and plume characteristics of the D-100 using krypton was conducted. Krypton was tested as part of an ongoing investigation of alternative propellants including mixtures of xenon and krypton, and pure krypton as an economical test propellant. Direct thrust measurements were taken to provide performance data. Thrust was measured indirectly using various probes and showed comparable results to direct thrust stand measurements. The data showed that specific impulses for krypton comparable to those achieved with xenon could be realized at flowrates approximately 1.5 times those on xenon. The efficiency on krypton ranged from 21 to 36 percent. While these results were twenty percent lower than comparable data on xenon, the use of xenon-krypton mixtures is expected to increase efficiency.

\section{Acknowledgments}

The authors wish to acknowledge Dr. Leonard Caveny of BMDO for his support of this research. The authors also thank Charles Garner, Jay Polk, and John Brophy of JPL, Tom Haag of NASA Lewis Research Center, Sang-Wook Kim and John Foster of PEPL, and Terry Larrow, Tom Griffin, and Gary Gould of the UM Aerospace Engineering Department for their intellectual and technical assistance on this project.

\section{References}

1. Garner, C.E., Brophy, J.R., Polk, J.E., Semenkin, S., Garkusha, V., Tverdokhlebov, S., and Marrese, C., "Experimental Evaluation of a Russian Anode Layer Thruster," 3rd Russian-German Conference on Electric Propulsion Engines and Their Technical Applications, Stuttgart, Germany, July 1994.

2. Sankovic, J.M., Haag, T.W., and Manzella, D.H., "Performance Evaluation of a $4.5 \mathrm{~kW}$ SPT Thruster," Proceedings of the 24th Intemational Electric Propulsion Conference, IEPC Paper 95-30, Moscow, Russia, Sept. 1995, pp. 246-253.

3. Spores, R., Birkan, M., Cohen, R., and Einhorn, R., "The U.S.A. Air Force Electric Propulsion Program," Proceedings of the 24th Intemational Electric Propulsion Conference, IEPC Paper 95-244, Moscow, Russia, Sept. 1995, pp. 1068-1084.

4. Garkusha, V.I., Grishin, S.D., Mironov, S.G., Savitsev, V.V., and Semenkin, A.V., "Electric Propulsion Activity at TSNIIMASH," Proceedings of the 24th International Electric Propulsion Conference, IEPC Paper 95-09, Moscow Russia, Sept. 1995, pp. 75-86.

5. Garner, C.E., et. al,"Evaluation of a $4.5 \mathrm{~kW} \mathrm{D-}$ 100 Thruster with Anode Layer". AIAA 96-2967,July 1996. 
Copyright (C)1996, American Institute of Aeronautics and Astronautics, Inc.

6. Semenkin, A.V. and Chislov, G.O., "Study of Anode Layer Thruster Operation with Gas Mixtures," Proceedings of the 24th International Electric Propulsion Conference. IEPC Paper 95-78, Moscow, Russia, Sept. 1995. pp. 521-526.

7. Brown. Sanborn C., Basic Data of Plasma phrsics. M.I.T. 1994. 